\title{
Prevalence of Diabetes and Impaired Fasting Glycemia in Patients With Oral Cancer: A Retrospective Study in Hungary
}

\author{
ADAM VEGH ${ }^{1,2}$, DOROTTYA BANYAI ${ }^{2,3}$, MARTA UJPAL ${ }^{1,2}$, KATA SARA SOMOGYI $^{2,4}$, \\ ZITA BICZO $^{2,4}$, GABOR KAMMERHOFER ${ }^{2,4}$, ZSOLT NEMETH ${ }^{1}$, \\ PETER HERMANN $^{5}$, MICHAEL PAYER ${ }^{2,6}$ and DANIEL VEGH ${ }^{2,5}$ \\ ${ }^{1}$ Department of Maxillofacial and Oral Surgery, Semmelweis University, Budapest, Hungary; \\ ${ }^{2}$ Diabetes-Dental Working Group, Semmelweis University, Budapest, Hungary; \\ ${ }^{3}$ Department of Pedodontics and Orthodontics, Semmelweis University, Budapest, Hungary; \\ ${ }^{4}$ Faculty of Dentistry, Dental Student, Semmelweis University, Budapest, Hungary; \\ ${ }^{5}$ Department of Prosthodontics, Semmelweis University, Budapest, Hungary; \\ ${ }^{6}$ Division of Oral Surgery and Orthodontics, Department of Dental Medicine and Oral Health, \\ School of Dentistry, Medical University Graz, Graz, Austria
}

\begin{abstract}
Background/Aim: Diabetes mellitus (DM) is one of the most common chronic metabolic disorders. Our research aimed to demonstrate the relationship between DM and oral cancer. Patients and Methods: We pursued a retrospective research study in Hungary between January 2019 and December 2020. We investigated 597 inpatient records and compared them to the results of our previous studies (1998-2002 and 2012-2015). Results: The frequency of patients with DM in the oral cancer group is 2.45 times higher today than 20 years ago. The prevalence rate of DM and oral malignancies increased from $14.6 \%$ to $35.8 \%$. In the oral cancer group, $54.4 \%$ of the patients had elevated blood glucose levels and of these, $61.1 \%$ of them had type 2 diabetes, $34.2 \%$ had impaired fasting glycemia, and only $4.7 \%$ had type 1 diabetes. We observed that $45.3 \%$ of them were smokers. Of those whose blood sugar levels were under 6.1 mmolll, the mean body mass index was 25.33 [standard deviation $(S D)= \pm 4.5$; range $=15.57-39.84]$, while among patients with $D M$, it was 26.92 ( $S D= \pm 5.8$; range $=18.36$ 44.08). Conclusion: It may be necessary to continuously monitor the patient's blood sugar level to maintain euglycemic levels when managing patients with malignant oral lesions.
\end{abstract}

This article is freely accessible online.

Correspondence to: Daniel Vegh, Department of Prosthodontics, Semmelweis University, H-1088 Szentkirályi Street 47, Budapest, Hungary. E-mail: vegh.daniel@dent.semmelweis-univ.hu

Key Words: Diabetes, oral cancer, public health, smoking, impaired fasting glycemia.
Diabetes mellitus (DM) is one of the most common chronic metabolic disorders characterized by elevated blood glucose levels. The pathophysiology of this disease is secondary to insulin secretion deficiency, dysfunction, or both (1). It has three main types: type 1 diabetes (T1D), type 2 diabetes (T2D), and gestational diabetes (GDM) (2). Unfortunately, there is an increasing trend in the number of patients living with diabetes (3). Most patients have T2D, which is preventable with a healthy lifestyle (4). In 2017, 451 million people were living with DM worldwide. According to the International Diabetes Foundation Atlas data, researchers predict this number to climb to 693 million by 2045 (5). According to the Hungarian Diabetes Association, more than 700,000 people are living with DM in Hungary. The prevalence of patients with diabetes and impaired fasting glycemia (IFG) in Hungary is $7.5 \%$ and $4 \%$, respectively (6). The prevalence rate of $\mathrm{T} 2 \mathrm{D}$ is noted to increase with age. The prevalence rate is $19 \%$ in people aged 60-70 years whereas it is $20 \%$ in those aged $>70$ years (7).

DM can cause serious, potentially life-threatening complications such as kidney failure (8), cardiovascular diseases (9), microangiopathy (10), retinopathy (11), and neuropathy (12). Moreover, DM can severely damage oral tissues. It increases the risk of periodontal diseases and tooth loss $(13,14)$, especially in combination with uncontrolled glycemia. People living with diabetes often experience xerostomia (15) and burning mouth syndrome (16), which usually lead to tasting dysfunctions (17). After oral surgeries, delayed wound healing can cause complications, such as dry sockets (18). Geographic tongue (19), lichen planus (20), and oral candidiasis (21) are more common among people with DM (22). Oral malignancies may be more prevalent in patients with DM. We aimed to demonstrate the relationship between DM and oral malignancies in this study. 
Table I. Comparing the results of three different examination intervals.

\begin{tabular}{|c|c|c|c|c|c|c|}
\hline & \multicolumn{3}{|c|}{ Oral cancer group } & \multicolumn{3}{|c|}{ Control group } \\
\hline & $1998-2002$ & $2012-2015$ & 2019-2020 & $1998-2002$ & $2012-2015$ & 2019-2020 \\
\hline Number of participants & 610 & 758 & 274 & 574 & 534 & 323 \\
\hline Men & $71.3 \%$ & $52.8 \%$ & $54.7 \%$ & $61.1 \%$ & $59.6 \%$ & $63.5 \%$ \\
\hline Women & $28.7 \%$ & $47.2 \%$ & $45.3 \%$ & $38.9 \%$ & $40.4 \%$ & $36.5 \%$ \\
\hline Mean age (years) & 56 & 64 & 68 & 51 & 53 & 47 \\
\hline Frequency of diabetes & $14.6 \%$ & $25.9 \%$ & $35.8 \%$ & $5.6 \%$ & $10.3 \%$ & $8.0 \%$ \\
\hline T1D & $2.2 \%$ & $2.0 \%$ & $7.1 \%$ & & & \\
\hline $\mathrm{T} 2 \mathrm{D}$ & $97.8 \%$ & $98.0 \%$ & $92.9 \%$ & & & \\
\hline Frequency of IFG & $9.7 \%$ & $20.6 \%$ & $18.6 \%$ & $5.5 \%$ & $10.5 \%$ & $9.9 \%$ \\
\hline Proportion of smokers & $68.0 \%$ & $57.7 \%$ & $45.3 \%$ & $27.0 \%$ & $41.2 \%$ & $35.9 \%$ \\
\hline
\end{tabular}

IFG: Impaired fasting glycemia.

\section{Patients and Methods}

Data collection. This is a retrospective research study conducted at the Semmelweis University, Department of Oral and Maxillofacial Surgery, Budapest, Hungary between January 1, 2019 and December 31, 2020. We included 597 inpatient medical records. We recorded the following information: age, sex, height, weight, smoking habits, presence of diabetes or IFG, and cause of the hospital admission. For patients diagnosed with oral malignancy, we registered the location of the tumor and its histological type. Body mass index was calculated as patient's weight in $\mathrm{kg} /$ (patient's height in $\mathrm{m})^{2}$. Exclusion criteria included patients under 18 years of age and those with a history of drug abuse.

We classified patients into the diabetes group if they were previously diagnosed with DM. IFG was considered for patients with fasting blood glucose levels between $6.1 \mathrm{mmol} / 1$ and 6.9 $\mathrm{mmol} / \mathrm{l}$ (23). We divided the participants into two groups, namely those diagnosed with oral malignancy as the experimental/oral cancer group and those without, the control group.

All data were stored using Microsoft Excel. Our research group conducted similar studies twice in the past 20 years [1998-2002 (24) and 2012-2015 (25)]. We compared our collected data from this study to the results of these previous studies (Table I).

Ethical approval. The study was conducted in accordance with the Declaration of Helsinki Ethical Principles and Good Clinical Practices and was approved at each site by the Ethical Committee of the Semmelweis University (Budapest, Hungary) (Ethical Approval Number: SE-RKEB 204/2018).

Statistical analysis. Data analysis was performed using Prism version 8.4.2 (464) software (Graphpad Software, San Diego, CA, USA) and data were reported as means \pm standard deviations (SDs) and range or absolute numbers with percentages. We used Pearson's Chi-squared test for statistical analysis. Differences below the $5 \%$ limit $(p<0.05)$ were considered significant.

\section{Results}

Of the 597 patients included in the study, the experimental group included 274 patients (45.9\%), comprising 150 men and 124 women. All patients were diagnosed with oral malignancies that were confirmed histologically. The mean age of the oral cancer group was 68 years $( \pm 12.9$; range $=33$ 96 years). Of the oral cancer group, $45.3 \%$ (124/274) were smokers. Approximately half of the patients with cancer, $54.4 \%$ (149/274), had elevated blood glucose levels. Of these patients, $61.1 \%(91 / 149)$ were diagnosed with T2D, 34.2\% (51/149) were classified into the IFG group, and only $4.7 \%$ (7/149) had T1D. The mean BMI was $25.33( \pm 4.5$; range $=15.57-39.84$ ) for those whose blood sugar levels were under $6.1 \mathrm{mmol} / 1$ and $26.92( \pm 5.8$; range=18.36-44.08) for those with DM. Based on the histological examination, the most common neoplasm was squamous cell carcinoma $(85 \%$, $233 / 274)$. The remainder consisted of basal cell carcinomas (6\%, 17/274), melanomas $(1 \%, 3 / 274)$, adenoid cystic carcinoma $(1 \%, 4 / 274)$, adenocarcinomas $(1 \%, 4 / 274)$, and other rarer types of malignancies. Most malignant tumors were located on the lips $(28.8 \%, 79 / 274)$, tongue $(19.0 \%$, $52 / 274)$, sublingual region $(18.6 \%, 51 / 274)$, or gingiva $(11.3 \%, 31 / 274)$. The prevalence of tumors in different locations was almost equal in patients with and without DM. The control group had 323 patients, comprising 206 men and 118 women. The mean age of the control group was 47 years $( \pm 17.3$; range $=18-91$ years $)$. Patients of this group were hospitalized due to facial trauma causing fractures of the mandible or midface $(45.5 \%, 147 / 323)$, orthognathic surgery $(15.8 \%, 5 / 3231)$, surgical removal of benign tumors $(11.8 \%$, $38 / 323)$, cysts of the jaws $(22.9 \%, 74 / 323)$, or treatment of other benign lesions $(4 \%, 13 / 323)$. We noted that the control group had $18.0 \%$ patients $(58 / 323)$ diagnosed with glucose metabolic disorders, of whom $9.9 \%(32 / 323)$ were with IFG and $8.0 \%$ (26/323) with diabetes. The prevalence of DM and IFG among patients with cancer were $35.8 \%$ (98/323) and $18.6 \%$ (51/323), respectively. Based on the statistical analysis, we concluded a significant difference between the two groups (DM groups $p<0.00001 v s$. IFG groups $p=0.002185$ ). More than one-third of the control group were smokers $(35.9 \%$, 
$116 / 323)$, which had a statistically significant difference with the oral cancer group $(45.3 \%, 124 / 274 ; p=0.020346)$.

\section{Discussion}

In this study, we aimed to demonstrate the relationship between DM and oral malignancies. This paper discussed the relationship between DM, smoking, and malignant oral lesions in terms of sex and age. We have shown that trends differ between the 1998-2002 and 2019-2020 periods in terms of average age, sex, DM incidence, and percentage of smokers. During the past decades, the incidence of oral cancer in patients with DM has increased by 2.5 times.

DM is one of the most significant public health diseases. For the past decades, it has been showing an alarming increase in incidence rates. Similar trends can be observed in terms of malignant oral lesions, wherein Hungary ranks among the highest in Europe in terms of morbidity and mortality rates (26).

Elevated glucose level accelerates the synthesis of tumor cell DNA and causes failure in oxidative balance mechanisms. It leads to the release of a multitude of growth factors and cytokines, which molecules facilitate the growth and spread of malignant cells. New advances in cancer therapy, like additional corticosteroid therapy, inhibit the translocation of GLUT-4 glucose transporter or mTOR inhibitors (PI3-K inhibitors), positively affecting the oncologic status. The specific mechanism remains unclear but understanding the relationship between neoadjuvant therapies and secondary diabetes could determine the optimum care for patients (27).

On comparing the results of this study with our previous data, we noted that the frequency of people with DM in the oral cancer group is 2.45 times higher today than 20 years ago. The incidence of confirmed DM had a statistically significant increase from $14.6 \%$ to $25.9 \%$ until 2015 and to $35.8 \%$ until 2020 ( $p=0.000657)$. Although the number of people with DM showed a rapid increase, the current proportion of people with IFG is in the same range as in 2015. For the oral cancer group, the demographics in terms of age and sex differed from that of our previous studies. The mean age of people in the current oral cancer group was 68 years compared to the mean of 56 years previously. Similarly, the ratio of women increased from $28.7 \%$ in 1998 to $45.3 \%$ in 2020 . The frequency of smoking shows a decreasing tendency both in the oral cancer and control groups. The proportion of smokers in the oral cancer group almost halved from $68 \%$ in our first study to $35.9 \%$ in this study. In the control group, there was an increase in the number of smokers between 1998 and 2015 from 28\% to $41.2 \%$ that later declined to $35.9 \%$. This may be because of the positive impacts of the strict laws and regulations of tobacco product selling in Hungary.

The incidence of DM among people with oral cancer has increased from $14.6 \%$ to $35.8 \%$ during the last 20 years. The increase in mean age may partly explain this trend because most people in our study were diagnosed with T2D, which is more common among the elderly. The increase in mean age can also result from the different ratio of men to women, which was $28.7 \%-71.3 \%$ in the $1998-2002$ study and $45.3 \%$ $54.7 \%$ in the current study. Malignant lesions in women are primarily diagnosed $15-20$ years after menopause.

Compared to the studies conducted 20 years ago, the incidence of diabetes, particularly T2D, has doubled among those with cancer. Because metabolic conditions associated with DM also affect tumor metabolism, treatment may result in tumor recurrence. Metformin, the primary drug of choice for the treatment of T2D achieved good results. Even the non-diabetic patients responded better to neoadjuvant and radiotherapy treatments (28), and patients with diabetes had a better tumor-specific two-year survival rate (29).

People with diabetes are considered a high-risk group in terms of dental diseases. Dental screening and care should be one of the pillars of comprehensive diabetes care, which is an opportunity we would like to create in the future. For people living with $\mathrm{T} 2 \mathrm{D}$, we recommend at least an annual dental check-up, which includes a stomato-oncological screening examination. Since 2015, our team has worked on the goal to better understand problems that arise during the dental care of patients with diabetes using our data and to help improve the quality of the patient's lives with these tests and experimental results (30). We were in constant collaboration with the Hungarian Diabetes Association, the International Diabetes Federation, and the dental department of the Hungarian Medical Association during these study periods. At Semmelweis University, Budapest, we provide free dental screening to patients with diabetes. This service is currently unique in the world. The purpose of the specialist clinic is that the annual dental check-up of patients diagnosed with diabetes should be integrated into clinical practice. We believe that prevention is the key to success.

In conclusion, we showed a significant increase in patients with diabetes and oral cancer. It may be necessary to continuously monitor the patient's blood sugar level and maintain it at euglycemic levels when managing patients with malignant oral lesions. Future research should evaluate whether dental screening programs are effective in detecting premalignant oral lesions in patients with diabetes.

\section{Conflicts of Interest}

The Authors have no conflicts of interest to declare in relation to this study.

\section{Authors' Contributions}

AV, DV: Conceptualization, Methodology, Software. DB, MU, PH, ZN: Data curation, Writing- Original draft preparation, Visualization, Investigation. SKS, ZB, GK: Supervision. MU, MP: Software, Validation. DV, MU: Writing- Reviewing and Editing. 


\section{Acknowledgements}

The Authors thank everyone who participated in the research.

\section{Funding}

This work was supported by Dr. András Korányi Foundation Research Grant 2020 (Balatonfüred, Hungary).

\section{References}

1 American Diabetes Association: Diagnosis and classification of diabetes mellitus. Diabetes Care 33(Suppl 1): S62-S69, 2010. PMID: 20042775. DOI: $10.2337 / \mathrm{dc} 10-$ S062

2 American Diabetes Association: 2. Classification and diagnosis of diabetes: Standards of medical care in diabetes-2019. Diabetes Care 42(Suppl 1): S13-S28, 2019. PMID: 30559228. DOI: $10.2337 / \mathrm{dc} 19-\mathrm{S} 002$

3 Galicia-Garcia U, Benito-Vicente A, Jebari S, Larrea-Sebal A, Siddiqi H, Uribe KB, Ostolaza H and Martín C: Pathophysiology of type 2 diabetes mellitus. Int J Mol Sci 21(17): 6275, 2020. PMID: 32872570. DOI: 10.3390/ijms21176275

4 Vargas-Ortiz K, Lira-Mendiola G, Gómez-Navarro CM, PadillaEstrada K, Angulo-Romero F, Hernández-Márquez JM, VillaMartínez AK, González-Mena JN, Macías-Cervantes MH, Reyes-Escogido ML and Guardado-Mendoza R: Effect of a family and interdisciplinary intervention to prevent T2D: randomized clinical trial. BMC Public Health 20(1): 97, 2020. PMID: 31969136. DOI: 10.1186/s12889-020-8203-1

5 Cho NH, Shaw JE, Karuranga S, Huang Y, da Rocha Fernandes JD, Ohlrogge AW and Malanda B: IDF Diabetes Atlas: Global estimates of diabetes prevalence for 2017 and projections for 2045. Diabetes Res Clin Pract 138: 271-281, 2018. PMID: 29496507. DOI: 10.1016/j.diabres.2018.02.023

6 Jermendy G, Nádas J, Szigethy E, Széles G, Nagy A, Hídvégi T, Paragh $\mathrm{G}$ and Adány R: Prevalence rate of diabetes mellitus and impaired fasting glycemia in Hungary: cross-sectional study on nationally representative sample of people aged 20-69 years. Croat Med J 51(2): 151-156, 2010. PMID: 20401958. DOI: $10.3325 / \mathrm{cmj} .2010 .51 .151$

7 Kempler P, Putz ZS and Kiss Z: Prevalence and financial burden of type 2 diabetes mellitus in Hungary between 2001-2014 results of the analysis of the National Health Insurance Fund database. Diabetol Hung 24: 177-188, 2016.

8 Pecoits-Filho R, Abensur H, Betônico CC, Machado AD, Parente EB, Queiroz M, Salles JE, Titan S and Vencio S: Interactions between kidney disease and diabetes: dangerous liaisons. Diabetol Metab Syndr 8: 50, 2016. PMID: 27471550. DOI: 10.1186/s13098-016-0159-z

9 Ziebolz D, Reiss L, Schmalz G, Krause F, Haak R and Mausberg RF: Different views of dentists and general medical practitioners on dental care for patients with diabetes mellitus and coronary heart diseases: results of a questionnaire-based survey in a district of Germany. Int Dent J 68(3): 197-203, 2018. PMID: 29274083. DOI: $10.1111 /$ idj.12353

10 Madonna R, Balistreri CR, Geng YJ and De Caterina R: Diabetic microangiopathy: Pathogenetic insights and novel therapeutic approaches. Vascul Pharmacol 90: 1-7, 2017. PMID: 28137665. DOI: $10.1016 /$ j.vph.2017.01.004
11 Wang W and Lo ACY: Diabetic retinopathy: Pathophysiology and treatments. Int J Mol Sci 19(6): 1816, 2018. PMID: 29925789. DOI: $10.3390 /$ ijms 19061816

12 Feldman EL, Nave KA, Jensen TS and Bennett DLH: New horizons in diabetic neuropathy: mechanisms, bioenergetics, and pain. Neuron 93(6): 1296-1313, 2017. PMID: 28334605. DOI: 10.1016/j.neuron.2017.02.005

13 Kocher T, König J, Borgnakke WS, Pink C and Meisel P: Periodontal complications of hyperglycemia/diabetes mellitus: Epidemiologic complexity and clinical challenge. Periodontol 2000 78(1): 59-97, 2018. PMID: 30198134. DOI: 10.1111/prd.12235

14 Sanz M, Ceriello A, Buysschaert M, Chapple I, Demmer RT, Graziani F, Herrera D, Jepsen S, Lione L, Madianos P, Mathur M, Montanya E, Shapira L, Tonetti M and Vegh D: Scientific evidence on the links between periodontal diseases and diabetes: Consensus report and guidelines of the joint workshop on periodontal diseases and diabetes by the International Diabetes Federation and the European Federation of Periodontology. J Clin Periodontol 45(2): 138-149, 2018. PMID: 29280174. DOI: $10.1111 /$ jcpe. 12808

15 López-Pintor RM, Casañas E, González-Serrano J, Serrano J, Ramírez L, de Arriba L and Hernández G: Xerostomia, hyposalivation, and salivary flow in diabetes patients. J Diabetes Res 2016: 4372852, 2016. PMID: 27478847. DOI: $10.1155 / 2016 / 4372852$

16 Borgnakke WS, Genco RJ, Eke PI, Taylor GW, Cowie CC, Casagrande SS, Menke A, Cissell MA, Eberhardt MS, Meigs JB, Gregg EW, Knowler WC, Barrett-Connor E, Becker DJ, Brancati FL, Boyko EJ, Herman WH, Howard BV, Narayan KMV, Rewers M and Fradkin JE: Oral health and diabetes. 2018. PMID: 33651538.

17 Silva MF, Barbosa KG, Pereira JV, Bento PM, Godoy GP and Gomes DQ: Prevalence of oral mucosal lesions among patients with diabetes mellitus types 1 and 2. An Bras Dermatol 90(1): 49-53, 2015. PMID: 25672299. DOI: 10.1590/abd1806-4841.20153089

18 Gadicherla S, Smriti K, Roy S, Pentapati KC, Rajan J and Walia A: Comparison of extraction socket healing in non-diabetic, prediabetic, and type 2 diabetic patients. Clin Cosmet Investig Dent 12: 291-296, 2020. PMID: 32765113. DOI: 10.2147/CCIDE. S264196

19 Al-Maweri SA, Ismail NM, Ismail AR and Al-Ghashm A: Prevalence of oral mucosal lesions in patients with type 2 diabetes attending hospital universiti sains malaysia. Malays $\mathbf{J}$ Med Sci 20(4): 39-46, 2013. PMID: 24043995.

20 Ying J, Xiang W, Qiu Y and Zeng X: Risk of metabolic syndrome in patients with lichen planus: A systematic review and meta-analysis. PLoS One 15(8): e0238005, 2020. PMID: 32822406. DOI: 10.1371/journal.pone. 0238005

21 Krishnan PA: Fungal infections of the oral mucosa. Indian J Dent Res 23(5): 650-659, 2012. PMID: 23422613. DOI: 10.4103/0970-9290.107384

22 Nazir MA, AlGhamdi L, AlKadi M, AlBeajan N, AlRashoudi L and AlHussan M: The burden of diabetes, its oral complications and their prevention and management. Open Access Maced J Med Sci 6(8): 1545-1553, 2018. PMID: 30159091. DOI: 10.3889/oamjms.2018.294

23 International Diabetes Foundation. IDF Diabetes Atlas, ninth ed. 2019, Available at: https://diabetesatlas.org/upload/resources/ material/20200302_133351_IDFATLAS9e-final-web.pdf [Last accessed on September 25, 2021] 
24 Ujpál M, Matos O, Bíbok G, Somogyi A, Szabó G and Suba Z: Diabetes and oral tumors in Hungary: epidemiological correlations. Diabetes Care 27(3): 770-774, 2004. PMID: 14988300. DOI: $10.2337 /$ diacare 27.3 .770

25 Végh D, Bányai D, Hermann P, Németh Z and Ujpál M: Type-2 diabetes mellitus and oral tumors in Hungary: a long-term comparative epidemiological study. Anticancer Res 37(4): 18531857, 2017. PMID: 28373451. DOI: 10.21873/anticanres.11521

26 Bosetti C, Carioli G, Santucci C, Bertuccio P, Gallus S, Garavello W, Negri E and La Vecchia C: Global trends in oral and pharyngeal cancer incidence and mortality. Int J Cancer 147(4): 1040-1049, 2020. PMID: 31953840. DOI: 10.1002/ijc.32871

27 Shariff AI, Syed S, Shelby RA, Force J, Clarke JM, D'Alessio D and Corsino L: Novel cancer therapies and their association with diabetes. J Mol Endocrinol 62(2): R187-R199, 2019. PMID: 30532995. DOI: 10.1530/JME-18-0002

28 Skinner HD, Sandulache VC, Ow TJ, Meyn RE, Yordy JS, Beadle BM, Fitzgerald AL, Giri U, Ang KK and Myers JN: TP53 disruptive mutations lead to head and neck cancer treatment failure through inhibition of radiation-induced senescence. Clin Cancer Res 18(1): 290-300, 2012. PMID: 22090360. DOI: 10.1158/10780432.CCR-11-2260
29 Stokes WA, Eguchi M, Amini A, Hararah MK, Ding D, McDermott JD, Bradley CJ and Karam SD: Survival impact and toxicity of metformin in head and neck cancer: An analysis of the SEER-Medicare dataset. Oral Oncol 84: 12-19, 2018. PMID: 30115470. DOI: 10.1016/j.oraloncology.2018.06.022

30 Banyai D, Vegh A, Biczo Z, Barone MTU, Hegedus T and Vegh D: Oral health knowledge and habits of people with type 1 and type 2 diabetes. Int Dent J, 2021. PMID: 34509286. DOI: 10.1016/j.identj.2021.07.003
Received October 4, 2021

Revised October 21, 2021

Accepted October 25, 2021 